\title{
AN INTERNATIONAL CROSS-DISCIPLINARY STUDENT COLLABORATION: A RETROSPECTIVE EIGHT YEARS
}

\author{
Paul S H Poh ${ }^{1}$, Stephen Austin², Robby Soetanto ${ }^{3}$ \\ ${ }^{1}$ Ryerson University (CANADA) \\ ${ }^{2}$ Coventry University (UNITED KINGDOM) \\ ${ }^{3}$ Loughborough University (UNITED KINGDOM)
}

\begin{abstract}
A successful construction endeavour invariably obliges a successful collaborative effort among its many multi-disciplinary stakeholders. Teachers of construction education today are increasingly aware of the need to teach their students skills to enable them to work collaboratively with their peers from other related disciplines. In the present day context of an increasingly globalized construction industry amidst a current rapid advancement in communication technology, an ability to work collaboratively with peers across a geographical divide within an online environment is a valuable skill to have. This paper presents the collective experiences of two distant universities where students from two related disciplines - architectural science (with a construction project management major) and civil engineering - collaborate on a joint student assignment across a time and geographical divide. It presents a description of the project and its intent, teaching pedagogy, students' feedback and the challenges of establishing the framework.
\end{abstract}

Keywords: Cross discipline collaborative learning, studio education, global collaboration.

\section{INTRODUCTION}

Few industries, if any, have not been unaffected by the present incessant drive of globalization. The construction industry is no exception, albeit not on a scale as large as the manufacturing or service industry. To some extent, there are elements of construction work that are not outsourceable. Trade professionals such as plumbers or carpenters can feel reasonably assured that they may not lose their jobs anytime soon, although the likelihood of imported cheaper labour cannot be entirely ruled out. The industry still needs its construction managers and supervisors to be present on the work sites in real time. Replacing them with less expensive out of location managers and supervisors appearing on a screen does not appear workable, at least for the foreseeable future.

Being an industry that is primarily profit driven, design and construction companies will continually seek ways and means to improve their bottom line. Although there are immoveable elements of work in the industry as outlined earlier, there are still many other elements that can be outsourced. For example, it is no longer uncommon to have the architectural and engineering design works carried out in different offices located in different countries. With a good level of collaboration and the support of current communication technology, the two teams should be able to function just as effectively as though they were collocated. If some elements of work can be done more cost effectively elsewhere, there is a good likelihood it will happen in an industry that is also well-known for its competitiveness. Some thirty or less years ago, if the design was done in the United Kingdom and the project was in Libya, reams of hand drafted drawings had to be printed, mailed or hand carried to the work site at the expense of dollars and time. Today, this same task can be achieved in seconds at virtually no cost.

Construction education teachers have a responsibility to impart upon their students skills to meet the industry's changing needs. This has been recognised by numerous educators and researchers for some time now. Anderson et. al. [1] shared some valuable lessons learned from a student project which involved several global multi-disciplinary teams who communicated using a BIM-enabled tool; Herrmann et. al. [2] recognized the importance of collaborative skills in the context of an increasing popularity in Integrated Project Delivery (IPD); Scott and Gosh [3] discussed a collaborative project by students from two distant universities; and, Poh et. al. [4] offered some circumstantial and anecdotal observations of students who participated on a student collaboration that involved three disciplines from three different institutions of higher learning. Other closely related works includes Leathem et. al. [5] on teaching pedagogy in a cross-disciplinary architecture/construction program; Childs et. al. [6] described students' experiences in virtual team working; Soetanto et. al. [7] on lessons learned when 
students from across disciplines, geographical and time divide collaborated; and, Soetanto et. al. [8] on performance and preferred modes of communication when students collaborated in virtual design teams. Soetanto et. al. [9] also offered key success factors and guidance for international collaborative design project; and discussed in general, virtual collaborative learning for building design [10].

This need to train our construction professionals to meet the demands of present-day and future industry needs have also be recognized by several construction and engineering accreditation bodies. The American Council for Construction Education (ACCE) requires graduates from their accredited schools to have skills as members of a multi-disciplinary team and be able to exploit web-based technology to manage the construction process [11]. The Canadian Engineering Accreditation Board (CEAB), established in 1936 as a federation of provincial and territorial authorities that license engineers and oversee the profession across Canada, did not go quite as far in its desired list of graduate attributes [12]. It simply requires "An ability to work effectively as a member and leader in teams, preferably in a multi-disciplinary setting". We believe that "preferable" may no longer be an option and inclusion of ability to work within a global dimension is apt and opportune.

Going back a decade, The Royal Academy of Engineering, United Kingdom recognized that engineers must have "the ability to work in globally dispersed teams across different time zones and cultures." It was this report [13] that prompted this collaboration. Whilst "Educating Engineers for the 21 st Century" made reference to engineers, we surmise that it is also relevant to all construction professionals and in particular construction project managers and coordinators. In a second report [14], the academy apprised that academia must supply graduates with skills that ensure their "employability". Within the context of an increasingly globalized world amidst a rapid improvement in communication technology, this must surely include interpersonal skill within an online environment and technical skills in the use of information technology.

\section{THE PROJECT}

This student collaboration started in 2010. It was made possible with an award from the 2010 Hewlett Packard Catalyst Initiative which encouraged STEM (Science, Technology, Engineering and Mathematics) educators and researchers to think beyond the traditional definition of STEM teaching. The theme from which the award was won is "Learning to create a better built environment". The objective was to use information and communication technology for a 21st century collaborative global education.

Herein Ryerson University (Canada) architectural science students teamed up with Coventry University (UK) civil engineering students to form project teams. A team or company typically comprises 2 students from each university. They prepare a Response to a client's Request for Proposal (RFP). In keeping with industry practices, the Response typically includes a schematic of their proposal supplemented with architectural and structural drawings, a preliminary cost estimate, a time schedule of their proposal from design conception to completion of construction and an environment assessment report. The call is usually for an Alteration \& Addition (A\&A) work for one of the university's academic buildings which no longer meets its current needs. A detailed list of issues pertaining to the building alongside some desired outcomes formed part of the project brief. A budget and an expected completion date are also provided.

At the end of the project the teams present their proposals to the client. Aesthetics, cost and duration are not the only main sell. In addition to their design philosophy and criteria such sustainability and minimal environmental impact, the teams also have to convince the client on how they can safely deliver their proposal on cost and on time. At the end of the collaboration, the students are encouraged to assess and reflect upon their experiences on the project.

Over the past eight years since this student collaboration first started, the number of students involved varied from year to year, from a low of 16 to high of 50 . The reason for this is the year to year fluctuations of architectural science students and our desire to keep the number of participating students from each institution the same. 


\section{THE INTENT}

There were a number of intentions for starting this student collaboration. They all buttress one central objective which is to equip our graduates with an ability to work collaboratively with peers across a geographical divide within an online environment. We believe this skill set is no longer be an option but obligatory in our present-day construction industry. We recognise that in many architectural and engineering schools it is still the norm for students to learn their disciplines within their "own precincts". For example, they could be involved in group assignments but they would be working with their peers from the same program. And for the most part, with peers whom they know socially or personally. We need to broaden this level of internal collaboration

Reality in the construction industry does not afford its professionals the choice of whom they want to work with. All too often, they are required to work with other professionals whom they have not met previously, as in a multi-disciplinary project team. Team members need not necessarily come from the same organisation. They could be from another, as in a joint venture endeavour. They could also be sited in another locale not within the same country and if that is the case they may have different working hours. Our present level of information technology today enables us to outsource just about any element of our design process to where they can be done more cost effectively. In a for profit industry, like the construction industry, it makes good business sense to do so if the opportunity arises.

\subsection{Have empathy for other disciplines}

Students learning within their "own precincts" creates two issues. The first is a dearth of understanding or awareness for another discipline. A common example is the close interconnectedness between architectural and structural designs. Changing spans or re-assigning floor usage is a task not too difficult for an architect. It could be readily done in AutoCAD but for the structural engineer it would involve a re-analyses of the structural frame - resulting in changes in member sizes and steel reinforcements in them. It would most probably require changes to the foundation design and invariably the work itself when it is carried out. We want to create this awareness that changes in the work of one discipline affects the work of another, and have empathy for other equally important disciplines.

\subsection{Experience in interactions with other disciplines}

The second issue that learning within one's precincts creates is a lack of interaction with peers who are not from the same program. We want our students to go beyond the experience of cooperating and collaborating with team members who are physically near to them. We want them to have an ability to cooperate and collaborate with team members whom they have not met physically. In an increasingly globalized world, this skill is important. We believe the dynamics are different. Soetanto et. al. $[7,8]$ espoused that many practices that are applicable to traditional collocated teams may no longer be relevant.

The construction industry is a people-centric industry, and has been since time immemorial. Being competent in mainstream technical knowledge and skills is not sufficient in an industry which depends to a large degree on being able to motivate people to achieve one's objective. This collaboration also provides the students an opportunity for some exercise in soft skills, which is experience in dealing with peers at arm's length. Team success demands a maximum level of communication and cooperation among team members. We aim to instill in them the importance of communication in a professional manner and the importance of soft skills in the industry.

\subsection{Learn the practices of another jurisdiction}

The assignments relate to a project in a particular country, and for students from the participating institution not in the country, this collaboration gives them an opportunity to learn the industry practices of another country. Their proposals have to meet the building codes and standards of the jurisdiction - for example, permissible floor loads, fire exits requirements, site constraints, health and safety considerations, and environmental regulations. In a cost estimate that is part of their submission, prices must reflect the locale. Where a proprietary wall envelope is proposed, the team must provide details of costs and benefits, and this normally involved contacting the supplier or fabricator. When the project is in its implementation stage, students must find out the protocol leading 
to permission to commence work. When construction equipment such as a tower crane is called for, students must not only know its capacity, reach or where to site it, they must also know where to source them from with approximate costs. All these require a fair deal of communication and discussion among the team members.

\subsection{Competence in communication technology}

The need to keep pace with the current rapid advance in communication technology is crucial in nearly all industries, and the construction industry is no exception. If use of a particular technology can reduce cost or time, there is a near certainty that it will be employed. Incompetency in an applicable technology is possibly an impediment to career growth. Throughout this collaboration, students use commercial software, GoToMeeting, to do their work. Although very little instructions were provided on how to use the software, students generally became quickly competent with its use - such as for reviewing a drawing or file with screen sharing and specifically pointing things out to clarify potentially obscure information. We do not discourage the use of any other platforms. Oftentimes, they would use Skype, Instant Messaging, set up Facebook accounts or WhatsApp group chats, in addition to emails and Drop Box. Dropbox proved to be useful in simplifying their work flow files kept in one place and accessible to all members.

In our endeavour to simulate industry practices, we set up a BIM-enabled portal where all information pertaining to the project such as drawings are available. The portal also hosts a forum. Students are required to direct all their questions to the forum. We believe this is important because each and every team then have all the same currency and level of information. We checked the forum daily and answer their questions. The forum is not limited to questions and clarifications, students are also encouraged to use it as a platform for discussions. Besides providing an integrated learning environment, we believe the forum also provides a more active and dynamic environment for learning.

\section{TEACHING PEDAGOGY}

A typical team size comprises four members - two from each participating institution. The teaching pedagogy is principally "learning by doing" within a studio setting. Students make use of knowledge from pre- and co-requisite courses learned in their lower years. Within each team, members will have knowledge of civil, structural, architectural and construction project management. As and when deemed necessary, lectures and seminars pertaining to particular aspects of the assignment were conducted.

From its commencement eight years ago, a studio setting has been used for this student collaboration for a number of reasons. First, we believe that students working in small groups towards a common goal encourage cooperative learning. Although the assignment does have a prescribed set of processes to accomplish intermediate goals, we believe what drives our students is largely because they are cognizant that their own success (translated in grades) is dependent on the teams' success.

The assignment is modelled closely to current industry practices and is designed to motivate and involve them deeply in the learning process. It is not content learning. It requires them to draw upon their technical knowledge to complete the Response successfully. They have to find all the relevant information they will need, and in so doing they also learned the importance of teamwork and communication skills. Although instructors are on hand to clarify particular issues and as resources, the responsibility for learning rests with the students. We believe this teaching pedagogy compels them to be self-directed, to think critically and to discover additional knowledge as they try to solve the problems associated with each phase of the project. We also believe that this sort of self-directed learning environment gives them a sense of individual fulfilment, something that would not be plausible through individualistic learning.

Students work with various means. They use GoToMeeting largely for its video conferencing and its screen sharing feature. Screen sharing allows them to work to work collaboratively in real time as they discuss the architectural and structural aspects of their design proposals. Emails still remain a common form of communication, but increasingly they set up Facebook accounts.

The total scheduled studio hours are nine hours per week in 2 sessions of five and four hours. They provide the main opportunity for them to develop their work. As the time difference between the two institutions is five hours, students frequently worked outside these scheduled hours when they have to 
meet online. It was observed that weekends are popular times for them to work together, often at the times between mid-mornings and early afternoons. We do not get involved with these out of school arrangements. Outside the scheduled 9 hours, they control their time and most reported that they put in more time than the prescribed nine hours.

\section{SOME CHALLENGES FACED}

Setting up collaboration as such requires commitment and support from the institutions. The faculty members involved need to acknowledge its educational advantages such as student experience and employability. Beyond the typical work required of getting a course ready, faculty members involved have to decide and agree on the contents of the assignment, due dates, grading criteria, and not least how to deal with disputes and complaints that sometimes arise among team members. It also calls for a high level of cooperation and communication between them throughout the duration of the collaboration. Its longevity is dependent on the continuing motivation of the faculty members involved.

The academic term at Ryerson University starts a full month ahead of Coventry University. It results in some difficulties in setting due dates for intermediate tasks and final submission, particularly for Coventry University students. It also means that Coventry University students have one month less time to complete the joint assignment, which on occasions caused some discontent.

Being a full month ahead also means that Ryerson University architectural science students start work on the project whilst their would-be peers are still on vacation. Typically, they would start work on the conceptual design and then offer it for discussion with their peers. This makes some Coventry students felt that they are in a "catch-up" situation.

There is also a time difference of 5 hours between Canada and the United Kingdom. It often creates difficulties for them to achieve synchronous interaction within their respective project/studio time table slots. It also means that students needed to be flexible with meeting times that were convenient for everyone. There were instances of students working unsocial hours so that they could hold on-line meetings. (Where there is no requirement to meet, students frequently used text-based communication app such as WhatsApp as other team members could then read their messages at any time and response if needed).

Some of our students reported challenges in working with team members from the other institution. Common complaints include no-show, non- or late delivery of commitments and sub-par work. In our experience, it also brings about a different set inter-personal dynamics [7, 8, 9].

Because Canada and the United Kingdom are not dissimilar in language and culture, there are minimal issues with these attributes. What did caused some issues were different technical terms used in each jurisdiction, an example being tap versus faucet. These, however, were quickly resolved.

\section{STUDENT FEEDBACK}

At the end of the joint assignment, students were encouraged to reflect upon their experiences, assured that their comments would have no bearings on their grades. For the most part, they reported positive experiences.

A recurring feedback is that working with distant team members requires additional time and energy, in scheduling meetings and working sessions, work integration and collective decision making. Scheduling times to meet online was often re-counted to be especially difficult as each team member would have his or her own full class schedules. Some have part-time employment, thus adding to the difficulty of finding a time that would work for everyone.

At the beginning of the collaboration, team members invariably subdivide the work among themselves. For the most part, they were allocated relevantly - for example architectural science students would be tasked to do the architectural aspects of the project and the civil engineering students the structural design. Some tasks would be shared such as cost estimates and the schedule. Allocating responsibilities and file exchanging protocol were frequently cited as challenges, and that setting and agreeing on ground rules at commencement helps. Over the past 8 years, there were about half a dozen feedbacks where students reported instances where one or more members of a team would leave the bulk of the work to the remaining team members. Some admitted that working 
with distant team members requires additional motivation. There were also instances where distant team members were perceived be apathetic - not paying attention and agreeing on everything.

Many, however, reported that working with distant team members provides an opportunity for social development within the safety of a school learning environment. They were excited to interact with team members whom they have not previously met, which is reflective of the construction industry when teams are formed specific to the project at hand. They cultivate good work ethics, learned how to manage their time and plan their own personal schedules. A number reported learning "valuable life skills" such as learning how to and accepting compromises.

What also come to light from the students' feedback was that working with distant team members was more challenging than working with their own classmates. Many were happy to accept it in return for a "learning experience in a real working world". Lessons learned include how to communicate professionally and how to deal with disputes and disagreement.

Although working with a time difference of five hours was sometimes seen as an issue with regard to meeting and working together times, it did work well in some aspects. Ryerson students frequently appreciated that by being five hours ahead of their Coventry team member, they could have their work for review or comments by morning the next day, if submitted by midnight. And this help ensured that work was continually done and not at a standstill.

We encouraged shared leadership, more accurately rotational leadership. The intention was to instill responsibility to each and every student the success or otherwise of their assignment. It also affords them a leadership experience and helps them take ownership of the project. Many students found this to be very positive aspect of the collaboration. Most reported that this helps to mitigate instances of "freeloaders" who does very little.

The greater part of their reflections relates to how this student collaboration had benefitted them. They learned that although there were little difference in culture between Canada and the United Kingdom, there are some differences in architecture, engineering and construction practices between Toronto and Coventry.

They also learned that their respective disciplines could make a difference on how they approach a particular task. For example, Ryerson architectural science students approach to a site analysis would largely be illustrative with minimal write-ups. In contrast, Coventry civil engineering students' would be a written report with very little graphics. Although it did cause some differences among a few teams, it was largely appreciated by many as reported in their reflections. Many students reported that their team took advantage of each other's strength and collaborated to presenting a report that is equally strong in graphics and written contents.

In summary, they felt that the experience was close to the real world - there is a client who use the building and who can provide factual information, they have a budget to work and all prices used must be reflective of the industry, there are time limitations and site constraints, and a requirement to communicate with team members and client via a Building Information Modelling (BIM) - enabled portal using the latest IT tools and means. Many Ryerson students also reported usefulness in learning and gaining experience with the United Kingdom building code and regulations.

\section{CONCLUSIONS}

The Ryerson-Coventry student collaboration is now in its $9^{\text {th }}$ year. Most of the students began with some apprehension about who are distant team members could be and what are their work ethics. The anxiety was largely about their grades being dependent on others whom they have never met and "who live in a faraway country". There were a handful of teams that did not perform as expected, a couple that required our mediation but the majority did well.

The joint assignment was designed to simulate industry practices. The students were required to research and find on their own current cost data, building codes and regulatory requirements for the jurisdiction. We believe it was this added dimension that help to motivate and involve them deeply in the learning process.

\section{ACKNOWLEDGEMENTS}

The authors acknowledge support from the following: 
1. Hewlett Packard Catalyst Initiative Grant which encouraged STEM (Science, Technology, Engineering and Mathematics) educators and researchers, 2010.

2. Higher Education Authority, UK, Teaching Development Grant, 2013

\section{REFERENCES}

[1] A. Anderson, C. S. Dossick, and L. Osburn, "Lessons learned from a BIM-enabled, multidisciplinary global team student project," 53rd ASC Annual International Conference Proceedings, pp. 73-81, 2017.

[2] M. M. Herrmann, A. D. Gregory, B. Miller, and S. Powney, "A retrospective of five years of a collaborative student design competition," 52nd ASC Annual International Conference Proceedings, pp. 1-8, 2016.

[3] L. Scott, and S. Ghosh, "Collaborative approach in construction education: towards a more constructivist experience," 52nd ASC Annual International Conference Proceedings, 2016.

[4] P. S. H. Poh, R. Soetanto, S. Austin, and Z. A. Adamu, "International multidisciplinary learning: an account of a collaborative effort among three higher education institutions," International Conference e-Learning Proceedings, pp. 389-3938, 2014.

[5] T. Leathem, E. M. McGlohn, A. Gregory, H. Herrmann, and L Carson, "A case study in pedagogy for a cross-disciplinary architecture/construction program," 51st ASC Annual International Conference Proceedings, 2015.

[6] M. Childs, S. Austin, R. Soetanto, J. Glass, Z. Adamu, C. Isiadinso, P. Poh, D. Knyazev, H. Tolley, and H. MacKenzie, "Virtual collaboration in the built environment," European Distance and E-Learning Network - EDEN Annual Conference Proceedings, 2014.

[7] R. Soetanto, M. Childs, P. Poh, S. Austin, and J. Hao, "Global multidisciplinary learning in construction education: lessons from virtual collaboration of building design teams," Civil Engineering Dimension, vol. 14, no. 3, pp. 173-181, 2012.

[8] R. Soetanto, P. Poh, S. Austin, J. Hao C. Katsanis, "Communication modes and performance of virtual design teams in an undergraduate building project," $28^{\text {th }}$ Annual Association of Researchers in Construction Management Proceedings, pp. 177-187, 2012.

[9] R. Soetanto, M. Childs, P. S. H. Poh, S. Austin, J. Glass, Z. A. Adamu, C. Isiadinso, H. Tolley and $\mathrm{H}$. MacKenzie, "Key success factors and guidance for international collaborative design projects", International Journal of Architectural Research, vol. 9, issue 3, pp. 6-25, 2015.

[10] R. Soetanto, M. Childs, P. Poh, S. Austin and J. Hao, "Virtual collaborative learning for building design," ICE Proceedings, Management Procurement and Law, vol. 167, issue 1, pp. 25-34, 2014.

[11] American Council for Construction Education, Accreditation, Accessed 02 April, 2018. Retrieved from http://www.acce-hq.org/accreditation/

[12] Canadian Engineering Accreditation Board, Draft Accreditation Criteria for the 2017-18 Cycle, Accessed 02 April, 2018. Retrieved from https://engineerscanada.ca

[13] The Royal Academy of Engineering, Educating Engineers for the 21st Century, Accessed 02 April, 2018. Retrieved from https://www.raeng.org.uk/publications/reports

[14] The Royal Academy of Engineering, Engineering graduates for industry, Accessed 02 April, 2018. Retrieved from https://www.raeng.org.uk/publications/reports 